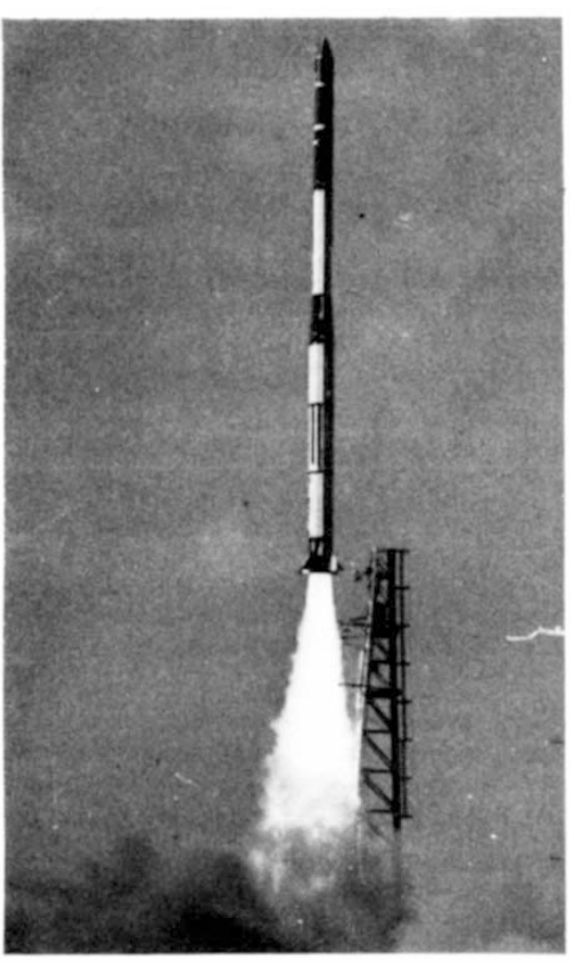

India: where next?

in 1979. Plans for further satellites include two more in the Rohini series. These will be larger than Rohini 1 and geared to specific scientific or applications tasks. India is also planning to launch an experimental telecommunications satellite, APPLE, on the third test flight of Ariane, the European launcher, next year.

The present SLV-3 rocket, based on NASA's Scout launcher, is too small, however, to launch some of the large satellites planned. Large liquid rocket motors are already being developed at the Vikram Sarabhai Space Centre on India's west coast for incorporation into future rockets capable of putting up to $800 \mathrm{~kg}$ into geosynchronous orbit.

The current launcher programme, which began in 1973, grew out of earlier experience gained in building sounding rockets at the Thumba equatorial rocket launching station.

Judy Redfearn

\section{Nuclear explosions}

\section{No alarm}

\section{Washington}

When can a cloud of dust particles resemble a nuclear explosion? When it is detected by a nuclear monitoring satellite, according to a report published last week by the US Office of Science and Technology Policy.

Spurred by speculation over the nature of a mysterious explosion apparently observed by a military Vela satellite over the lower Atlantic ocean last September, OSTP set up a panel of inquiry chaired by Dr Jack Ruina of the Massachusetts Institute of Technology.
The panel was at first inclined to agree with defence of ficials who claimed that the satellite had detected a clandestine nuclear explosion carried out by the South African Navy either on its own initiative or in collaboration with Israel.

After intense scrutiny of the data from the satellite, however, the panel now says that the flash of light seen by the satellite was "probably not" a nuclear explosion. Its alternative hypothesis is that the satellite was hit by a small meteroid, possibly as small as a speck of dust, and that this dislodged paint chips or other particles from the satellite's surface, which subsequently reflected sunlight into its detectors.

In support of this hypothesis, the scientists cite discrepancies in the data from the satellite's two sensors, indicating that the source may have been considerably closer to one sensor than the other.

In addition, there was a lack of any other evidence detected by stations on the ground - such as increased radiation or seismic activity - which would have corroborated the explosion hypothesis. Nor were there intelligence reports that a nuclear test had been carried out by either country. The Defense Intelligence Agency is not convinced. Before the OSTP report was released, the DIA leaked to the press its own conviction that a nuclear explosion had indeed been detected by the satellite, and that it had been carried out under weather conditions chosen to make detection difficult.

The White House, however, has adopted as its official position the OSTP panel's conclusion that there is insufficient evidence to prove a clandestine weapons test. According to State Department officials, this is the view that will prevail when a report on the incident is made to the Nuclear Non-Proliferation Treaty review meeting in Geneva next month.

David Dickson

\section{Nuclear power}

\section{Ore running out?}

The year just past was "another year of lost opportunities" according to the Nuclear Energy Agency (NEA), the OECD's own organization for the promotion of civil nuclear power. In its most recent annual report (the Eighth Activity Report covering 1979), the agency says that the growth of nuclear energy production in 1979 was a disappointing 2.2 per cent, compared with the average growth rate of 27.5 per cent a year during the period 1968-78. The pace of growth has paradoxically declined since the oil price rises of 1973 .

On the face of things, however, the figures are not too bad. According to the report, there were 232 civil nuclear plants in operation at the end of 1979 , and a further 229 under construction or on order, only seven more than in the previous year. New orders were almost offset by cancellation in West Germany, Spain and the United
States.

Whatever happens to new orders, the output of nuclear electricity in the OECD area in 1990 is now almost certain to be between 33 per cent and 40 per cent of the energy equivalent of oil imports in that year, according to figures quoted in the report. The hiatus in the projected growth of the nuclear industry in 1979 is attributed to the international concern with nuclear proliferation, the Three Mile Island accident, uncertainty about waste disposal and "the related problems of public understanding",

On the consequences of the Three Mile Island accident, the NEA follows a judicious line. Its report says that the accident showed that nuclear power is not accident-free, that defence in depth can work in practice but also that the accident "has revealed a number of deficiencies in the way that reactor safety has been approached up to now"'. It urges that more attention should be paid to the malfunctioning of other than major items of equipment, and promises to do what it can to help.

One consequence of last year's hesitation about nuclear power is, according to NEA, that the uranium mining industry has become overcautious, thus threatening future growth.

World uranium reserves at costs up to $\$ 80 / \mathrm{kg}$ of uranium metal (the present economic limit on production) have increased by some 200,000 tonnes in the past two years, and now total 1.85 million tonnes. The increase came mainly from discoveries in Brazil and Canada and "improved knowledge" of deposits in Namibia, South Africa, Spain and the United States. NEA estimates that these reserves match the needs of Western nuclear power programmes between now and 2000-2005 but also considers that a significant portion of ore now identified will not be recovered "for technical or political reasons". So, the argument goes, there is an "urgent need" for the discovery of additional resources, reinforced by the wide range of the projections for nuclear power in 2025 . The cumulative uranium requirements by that date range from 3.4 to 12 million tonnes, depending on nuclear power growth, the extent of reprocessing and the degree of development of fast breeders.

The NEA also looks forward to the exploitation of leaner ores, capable of yielding uranium at a cost of $\$ 130 / \mathrm{kg}^{-1}$. Its upper estimate of the quantity of uranium in reserves now identified, not all of them explored, is put at 5.04 million tonnes, a quantity comparable with the estimated need of the nuclear industry by the second decade of the next century unless breeder technology is applied rapidly. Thus, the report concludes, the viability of the industry at the turn of the century will depend on the success of exploration in the coming ten years.

Robert Walgate 